\title{
Kaposi's Sarcoma Associated with Gastrointestinal Bleeding: A Rare Complication of Long-Term Corticosteroid Therapy
}

\author{
Angèle Azon-Kouanou1, Djimon Marcel Zannou1, Kouessi Anthelme Agbodande1, \\ Cossi Angelo Attinsounon ${ }^{2}$, Albert Dovonou ${ }^{2}$, Roberto Dossou Torès Kouassi Prudencio', \\ Dédé Priscillia Tatiana Baglo1, Fabien Houngbe ${ }^{1}$

\footnotetext{
${ }^{1}$ National Teaching Hospital-HKM of Cotonou, University of Abomey-Calavi, Abomey-Calavi, Benin

${ }^{2}$ Departmental Hospital of Borgou-Alibori, University of Parakou, Parakou, Benin

Email: angele.azonkouanou@gmail.com,djmzannou@yahoo.fr, agbotem@yahoo.fr, acosange@yahoo.fr, dovcom1@yahoo.fr, prudenciotores@gmail.com, tatianabag@yahoo.fr, fab2012jos@yahoo.com
}

Received 23 October 2015; accepted 29 November 2015; published 2 December 2015

Copyright (C) 2015 by authors and Scientific Research Publishing Inc.

This work is licensed under the Creative Commons Attribution International License (CC BY). http://creativecommons.org/licenses/by/4.0/

(c) (i) Open Access

\begin{abstract}
Corticosteroid therapy has revolutionized the treatment of many diseases in medicine. The most concerned diseases are chronic inflammatory diseases. Its use may be either short-term or long-term, thus generating several side effects, some of which are conventional and known, but others are rare, such as Kaposi's sarcoma. We report here a particular clinical observation. Observation: This is a patient of 37 years, who consults in Internal Medicine for the treatment of mucocutaneous lesions, papular nodular, hyper pigmented, budding and disseminated appeared after six months of corticosteroid therapy. This treatment was introduced for the treatment of acoustic neurinoma. The patient is not diabetic or alcoholic and has a negative HIV status. The diagnosis of Kaposi's sarcoma was made by histology of biopsied skin lesions which concluded for a regular proliferation without atypia spindle cell or mitosis. The lesions persisted over a month despite discontinuation of corticosteroid therapy. Treatment with Bleomycin was necessary. The outcome was favorable under treatment with progressive and complete disappearance of lesions after 15 treatments. Conclusion: The classical side effects of long-term corticosteroid are known, but Kaposi sarcoma complicating long-term corticosteroid is rare in the literature. It is vital that any long-term corticosteroid should be the subject of careful and regular monitoring.
\end{abstract}

\section{Keywords}

Kaposi Sarcoma, Long-Term Corticosteroid, Rare Adverse Effects 


\section{Introduction}

The anti-inflammatory properties of corticosteroids are used therapeutically since 1948, revolutionizing the treatment of many diseases [1]. A good management of the treatment can minimize and even prevent adverse reactions responsible for their bad reputation [1]. The corticosteroid therapy is widely used in current medical practice. This use applies to all medical specialties, namely Internal Medicine that the most commonly prescribed in the system diseases such as systemic lupus erythematosus in 33\% of cases, and Horton's disease in 15\% of cases [2]. It can be used in short-term or prolonged. Its long-term use is responsible for many adverse effects such as lipodystrophy, skin trophic disorders, neuropsychiatric disorders, and insomnia reported by Fardet et al. in 2011 in France [2]. These side effects are conventional, but others such as Kaposi's sarcoma, are rare. We report the clinical observation of a Kaposi's sarcoma-induced long-term corticosteroid in a patient without other factors of immune suppression.

\section{Observation}

It is a patient of 37 years old; he isaccounting officer, followed by throat specialist for a neurinoma. It is a neurinoma of the hypoglossal nerve. It was a benign tumorconfirmed by the pathologist. In his medical history, there was no diabetes or cancer. He didn't take alcohol.There wereno family history of diabetes or cancer. Any other factors of immunosuppression were not identified.

His treatment was made by Betamethasone (Célestène $\left.{ }^{\circledR}\right) 6$ mg tablets per day. After 6 months of treatment, had appeared gradually, painful swelling of the lower limbs, and then secondarily mucocutaneous lesions, papular nodular hyper pigmented, budding and disseminated. What motivated his hospitalization in support for service. There is no history of diabetes, or to alcoholism.

The admission clinical examination showed a poor general condition with WHO performance status of 3 to 4, mucous cutaneous pallor. The weight was $70 \mathrm{~kg}$ for a height of $1 \mathrm{~m} 90$ (body mass index was $18.8 \mathrm{~kg} / \mathrm{mm}^{2}$ ), the blood pressure: $100 / 60 \mathrm{mmHg}$, temperature $37.7^{\circ}$ Celsius. On the mucocutaneous plane, there is an infiltration of the feet giving an aspect of kaposi's lymphangit. At the foot lymphangite associate in papulo nodular lesions, hyper pigmented, extending to the lower limbs. The left big toe is the site of kaposi's lymphangit (Figure 1).

These lesions also extend to the palms (Figure 2), buttocks, and back. In the Scrotum are immediately nodular vary in size, hyper pigmented purplish (Figure 3). The review Otorhino throat, noted the presence of purulent postnasal drip. The oropharynx is the seat of a purple lupus closet more or less sharp boundary, covered with a whitish deposit (Figure 4).

During hospitalization, gastrointestinal bleeding occurred in such great abundance of hematemesis making evoke a gastric localization of Kaposi's sarcoma.

The paraclinical examination including histology of skin lesions biopsied concluded the diagnosis of Kaposi's sarcoma showing the presence of a steady proliferation without atypia spindle cell or mitosis. Due to the lack of the equipment needed to make pictures of pathological images, we could not associate these illustrations.

The upper endoscopy performed in search of gastrointestinal sarcoma (gastric or duodenal) has instead revealed the presence of a large duodenal gastric ulceration and bleeding. The diagnosis of gastric and duodenal ulcer was made. We couldn't donebiopsies because of the abundance of the bleeding.

The blood count showed anemia with hemoglobin regenerative microcytic hypochromic $7 \mathrm{~g} / \mathrm{dl}$, the white count was 8 gigabytes per liter, predominantly neutrophils $60 \%$. The chest radiograph was normal transaminases

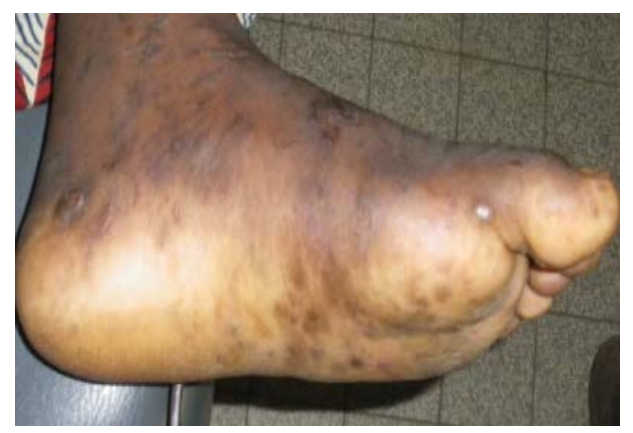

Figure 1. Kaposi’s lymphangit of the left foot. 


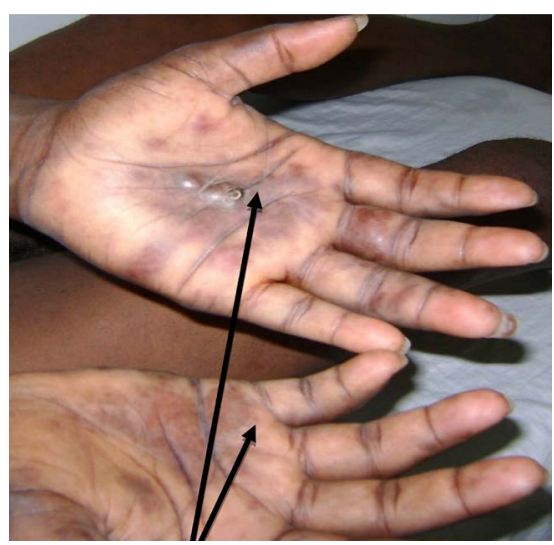

Figure 2. Papulo nodular lesions of Kaposi in the hands.

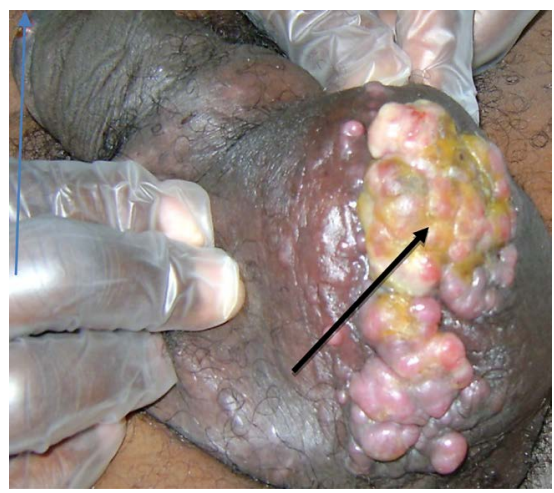

Figure 3. Nodular lesions of Kaposi.

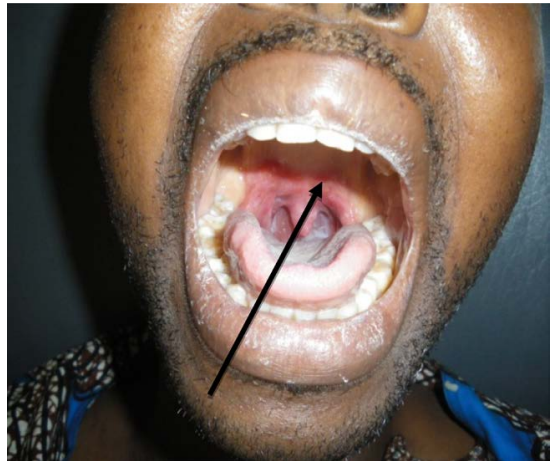

Figure 4. Kaposi's lesions in the throat.

were normal, an inflammatory syndrome is noted with an erythrocyte sedimentation rate of $120 \mathrm{~mm}$ in the first hour and C-reactive protein $80 \mathrm{mg} / \mathrm{l}$.HIV test was negative. TPHA and VDRL were also negative. Blood sugar levels was $0.97 \mathrm{~g} / \mathrm{dl}$, protein electrophoresis was normal. An abdominal ultrasound performed in order to search profound lymphadenopathy or abdominal mass was normal. Despite the young age of the patient, a prostatebladder ultrasound was done and don't identify any malignancy. The chest $\mathrm{X}$ rayshows no expansion of the mediastinum nor pulmonary abnormalities.

The support consisted of the patient's resuscitation (taking a venous, Rh blood grouping, blood transfusion group iso rhesus iso). Then, a proton pump inhibitor was administered through parenterally associated with the sequential treatment of eradication of Helicobacter pylori. Corticosteroid was gradually stopped.

The outcome was favorable marked by cessation of hematemesis. There are no signs of adrenal insufficiency observed. But there is persistence of lesions of Kaposi requiring the use of chemotherapy with bleomycin infusion, 
due to a cure every 3 weeks. The disappearance of lesions was progressive but complete after 15 treatments. The patient was reviewed two years after the cures and well.

\section{Discussion}

Kaposi's sarcoma deases (MK) is a mesenchymal proliferation of viral origin. It is described for the first time in 1872 by a Hungarian dermatologist Moritz Kaposi Sarcoma to as multiplex idiopathicum pigmentosum [3]. This is not until later in 1994 Chang end al discovered that herpes virus 8 (Kaposi's sarcoma herpes virus KSHV or HHV-8) was the causative agent [4]. The disease was confined to the lower limbs and evolved so indolent and above, reached mainly men aged Jewish or Mediterranean strain originated in Eastern Europe [4]. It was only later that Kaposi's sarcoma has been described in Africa [5] [6]. In this case, the location of lesions actually started by the lower limbs, and gradually it has spread not only to diffuse to other parts of the body, but also in the oral mucosa.

Clinico-epidemiological four forms of Kaposi's sarcoma have been described. This is the classic mediterranean or Kaposi's diseases, iatrogenic occurring after transplantation of organs or iatrogenic immunesuppression, epidemic Kaposi's diseases AIDS-related, and endemic or African Kaposi's diseases corresponding to the forms described in sub-Saharan Africa before the HIV epidemic [7]. Our patient meets the criteria for classification of the second clinical-epidemiological form that is to say, the iatrogenic Kaposi's diseases occurring after organ transplantation or iatrogenic immunosuppression. Obviously, the patient had no organ transplant, but he had a long-term corticosteroid therapy. It is therefore an iatrogenic immunosuppression, which perfectly fits this classification.

Fourteen (14) Kaposi's diseases iatrogenic patients were collected over 21 years in Morocco by Lamchahab et al. in 2011 [8], indicating the rarity of these cases. All were treated with corticosteroids, associated with Cyclophosphamide in three cases and in one case the Azathioprine. Other publications found in the literature were mostly reported clinical cases [9]. These patients had received long-term corticosteroid for severe asthma [9], rheumatoid arthritis [10]-[12], a Horton's diseases [13], psoriasis [14] or chronic pain on both knees [15].

The exposure time immunosuppressants prior to the occurrence of the Kaposi's diseases is 7 years for some authors Bruet et al. [9], and from 8 years for other Mohiuddin Wani, et al. [15]. The duration of exposure of our patient corticosteroids was 6 months, which is short in terms of time limits reported by other authors; but it is, however, a long-term corticosteroid therapy too. The occurrence of the Kaposi's diseases was home early compared to other cases reported and yet there are no other causes of immunosuppression. This indicates once again the originality of the clinical case.

The classic Kaposi's diseases generally affects older people with a peak incidence after the sixth decade of life [16], The age of onset in the Kaposi's diseases iatrogenic depends on the age of patients at the time of transplant and/or the introduction of immunosuppressive treatment described with an average around 40 years [17]. The patient's age at diagnosis was 37 years, which is lower than that found by Zaraa Tunisieen et al. in 2012 [18]. It is also lower than those of patients described by some authors in the published clinical cases through [9]-[13] which ranged in age from 58 years to 75 years. None of these patients were infected with HIV.

By cons, Chakib et al. [7] in Morocco have found in their study of 50 patients infected with HIV and suffering from Kaposi's diseases that the average age of patients was 32.5 years, ranging from 24 - 57 years. HIV infection occurs most often in patients in full sexual activity, therefore this age. This could explain the young age of patients, if other factors are not identified immunodepressions. Our patient is young (37 years) is not infected with HIV and has no other risk factor of immunosuppression.

Male dominance is clear in all forms of Kaposi's diseases. It would be difficult to make a relevant comment because it is home of a clinical case, while I Zaraa et al. [18] have described a series of 75 clinical cases collected in 25 years in Tunisia with a male predominantly male ( 49 men out of 75 cases). The mean age was 69.16 \pm 13.86 years. The average time of consultation is 34.6 months \pm 49.4 with extremes ranging from 20 days to 21 years.

Kaposi's diseases is multifocal cutaneous and visceral term [7]. Indeed, lesions here are essentially cutaneous mucosa. The gastrointestinal bleeding occurred in our patient made us suspect a particular location of the gastric digestive MK, especially in this context where there is a breach of the oral mucosa. The digestive involvement in Kaposi's sarcoma is most often asymptomatic, discovered only at autopsy according Rejeb et al. [19]. It can be manifested by epigastric pain, intermittent diarrhea, malabsorption syndrome, protein-losing enteropathy or 
ascites [20] [21]. Our patient had none of these signs. The gastrointestinal bleeding may be the result of a digestive location of the Kaposi's diseases. What motivated the realization of high endoscopy, which has not found a Kaposi's sarcoma.

The diagnosis of gastrointestinal involvement is based on the clinical and endoscopic appearance, often characteristic. Indeed, the upper gastrointestinal performed, showed a large gastric and duodenal ulcer bleeding and found a gastritis and duodenitis. This is in favor of the aggressiveness of the gastric mucosa by anti-inflammatory drugs. This side effect was known, which explains the systematic prescription of inhibitors of proton pump as adjunctive therapy to treatment with anti-inflammatory drugs, whether steroid or not.

Biopsies are indeed often negative due to the location in the submucosa of the tumor. In the literature, only $15 \%$ to $20 \%$ of biopsies under endoscopy are positive for Kaposi's sarcoma [22]. The biopsy was not carried out in our patient because of the local intensity of the bleeding. It would be difficult to confirm the absence of gastric location of the Kaposi's sarcoma in our case. The realization of several sets of biopsies is recommended as of 4 sets of biopsies performed by Ben Abdelkhalek Rejeb et al. [21], only one set on the 4 confirmed the diagnosis of Kaposi's sarcoma.

In the kaposi's diseases iatrogenic, the first treatment procedure is the reduction or modification of immunosuppressive therapy, which is usually accompanied by partial or complete regression of the lesions. Despite the gradual decline until the complete cessation of corticosteroid therapy, the lesions have not decreased in contrast to what was described by Morand et al. in 2007 [6], and Mohiuddin Wani Ghet et al. in 2012 [5]. The treatment used was Bleomycin, due to a cure every three weeks. A total of fifteen treatments were carried out with a progressive and complete remission of the lesions. There is no recurrence at two years of follow up.

\section{Conclusion}

Kaposi's disease complicating long-term corticosteroid is rare in the literature. The cases that described Kaposi's disease are most associated with HIV infection. The Kaposi's disease also occurs in immunocompetent. It is vital that any long-term corticosteroid should be the subject of careful and regular monitoring.

\section{References}

[1] Chosidow, O. and Lebrun-Vignes, B. (2007) Corticothérapie par voie générale. Annales de Dermatologie et de Vénéréologie, 134, 942-948. http://dx.doi.org/10.1016/S0151-9638(07)78255-8

[2] Farde, L., Blanchon, T., Perdoncini-Roux, A., Kettaneh, A., Tiev, K., Turbelin, C., Dorleans, Y., Chalet, J. and Hanslik, T. (2009) Perception par les médecins internistes de la fréquence et de la gêne induite par les effets indésirables d’une corticothérapie systémique prolongée. La Revue de Médecine Interne, 30, 113-118. http://dx.doi.org/10.1016/j.revmed.2008.08.004

[3] Kaposi, M. (1872) Idiopathic Multiple Pigmented Sarcoma of the Skin. Archiv für Dermatologie und Syphilis, 4, 265273. http://dx.doi.org/10.1007/BF01830024

[4] Chang, Y., Cesarman, E., Pessin, M.S., Lee, F., Culpepper, J., Knowles, D.M. and Moore, P.S. (1994) Identification of Herpes Virus + Like DNA Sequences in AIDS Associated Kaposi’s Sarcoma. Science, 266, 1865-1869. http://dx.doi.org/10.1126/science.7997879

[5] Mohiuddin Wani, G.H., Ahmad, S.M., Qayoom, S.M., Khursheed, B. and Khan, A.R. (2012) Corticosteroid Induced, HHV-8 Positive Kaposi’s Sarcoma in a Non-HIV Elderly Patient. JIMA, 44, 2-4.

http://www.ncbi.nlm.nih.gov/pmc/articles/PMC3708632/ http://dx.doi.org/10.5915/44-1-9317

[6] Morand, J.J., Lightburn, E.F., Simon, F. and Patte, J.H. (2007) Actualités de la Maladie de Kaposi. Médecine Tropicale, 67, 123-130.

[7] Chakib, A., Hliwa, W., Marih, L. and Himmich, H. (2003) Maladie de Kaposi au cours de l'infection par le VIH au Maroc. (A propos de 50 cas). Bulletin de la Société de Pathologie Exotique, 96, 86-89.

[8] Lamchahab, F.E., Tadlaoui, I., Beqqal, K., Bouattar, T., Ouzeddoun, N., Bayahia, R., Aitourhroui, M., Senouci, K., Hassam, B. and Ismaili, N. (2011) La Maladie de Kaposi iatrogène au Maroc en dehors du contexte de la transplantation. Annales de Dermatologie et de Vénéréologie, 138, 729-735. http://dx.doi.org/10.1016/j.annder.2011.06.007

[9] Bruet, A., Mahe, A., Sei, J.F., Mathe, C., Felsenheld, C., Lechevalier, L. and Fendler, J.P. (1990) Kaposi’s Sarcoma Complicating Long-Term Corticotherapy for Severe Asthma. La Revue de Médecine Interne, 11, 322-324. http://dx.doi.org/10.1016/S0248-8663(05)80867-7 
[10] El Bouchti, I., Akhdari, N., Amal, S. and El Hassani, S. (2009) Association d'une polyarthrite rhumatoïde et d'une maladie de Kaposi: A propos d’un cas. Résumé Sélectionné (Me.56) au congrès de la Société Française de Rhumatologie. http://www.rhumatologie.asso.fr/data/ModuleProgramme/PageSite/2009-1/Resume/5037.asp

[11] Casoli, P. and Tumiati, B. (1992) Rheumatoid Arthritis, Corticosteroid Therapy and Kaposi’s Sarcoma: A Coincidence? A Case and Review of Literature. Clinical Rheumatology, 11, 432-435. http://dx.doi.org/10.1007/BF02207213

[12] Schottstaedt, M.W., Hurd E.R. and Stone, M.J. (1987) Kaposi's Sarcoma in Rheumatoid Arthritis. The American Journal of Medicine, 82, 1021-1026. http://dx.doi.org/10.1016/0002-9343(87)90168-9

[13] Leung, F., Fam, A.G. and Osoba, D. (1981) Kaposi’s Sarcoma Complicating Corticosteroid Therapy for Temporal Arteritis. The American Journal of Medicine, 71, 320-322. http://dx.doi.org/10.1016/0002-9343(81)90135-2

[14] Meynadier, J., Guilhou, J.J., Peyron, J.L. and Guillot, B. (1981) Maladie de Kaposi chez un psoriasique soumis à une corticothérapie locale massive et prolongée. Clinique de Dermatologie et Syphiligraphie, Hôpital Saint-Charles, Montpellier, France. Dermatologica, 162, 417-423. http://dx.doi.org/10.1159/000250310

[15] Laor, Y. and Schwartz, R.A. (1979) Epidemiologic Aspects of American's Kaposi's Sarcoma. Journal of Surgical Oncology, 12, 299-303. http://dx.doi.org/10.1002/jso.2930120403

[16] Iscovich, J., Boffetta, P., Franceschi, S., Azizi, E. and Sarid, R. (2000) Classic Kaposi Sarcoma: Epidemiology and Risk Factoring. Cancer, 88, 500-517. http://dx.doi.org/10.1002/(SICI)1097-0142(20000201)88:3<500::AID-CNCR3>3.0.CO;2-9

[17] Schwartz, R.A. (1996) Kaposi’s Sarcoma: Advances and Perspectives. J Am Acad Dermatol, 34, 804-814. http://dx.doi.org/10.1016/S0190-9622(96)90018-3

[18] Zaraa, I., Labbène, I., El Guellali, N., Alaya, N.B., Mokni, M. and Osman, B.A. (2012) La maladie de Kaposi: Caractéristiques épidémio-cliniques, anatomopathologiques et thérapeutiques à propos de 75 cas. La Tunisie Médicale, 90, 116-121.

[19] Rejeb, B.A., Ebdelli, N., Bouali, R.M., Goucha, A., Bougrine, F., Khediri, F. and Delsol, G. (2001) Sarcome de Kaposi digestif primitif avec lymphocytopénie CD4 idiopathique, VIH négatif, HHV8 positif. Gastroentérologie Clinique et Biologique, 25, 707-710.

[20] Benjamin, P., Brownlee, N., Jain, A., Alwood, K., Dorman, S. and Agwu, A. (2006) Prolonged Diarrhea, Protein Losing Enteropathy, and Intestinal Perforation: An Illustrative Case of Kaposi Sarcoma HIV-Associated. The Internet Journal of Gastroenterology, 5, 1-6. http://ispub.com/IJGE/5/2/6133

[21] Lin, O., Scholes, J.V. and Lustbader, I.J. (1994) Chylous Ascites Resulting from Kaposi’s Sarcoma in an AIDS Patient. The American Journal of Gastroenterology, 89, 2252-2253. http://www.ncbi.nlm.nih.gov/pubmed/7977258

[22] Friedman, S.L., Wright, T.L. and Altman, D.F. (1985) Gastrointestinal Kaposi’s Sarcoma in the Patients with Acquired Immunodeficiency Syndrome. Endoscopic and Autopsy Findings. Gastroenterology, 89, 102-108. http://www.ncbi.nlm.nih.gov/pubmed/4007399 